\title{
Challenges in optimizing chemoradiation in locally advanced non small-cell lung cancers in India
}

\author{
Sushma Agrawal
}

\begin{abstract}
Data supporting use of concurrent chemoradiation in locally advanced lung cancers comes from clinical trials from developed countries. Applicability and outcomes of such schedules in developing countries is not widely reported. There are various challenges in delivering chemoradiation in locally advanced non small cell lung cancer in developing countries which is highlighted by an audit of patients treated with chemoradiation in our center. This article deals with the challenges in the context of a developing country. We conclude that sequential chemoradiotherapy is better tolerated than concurrent chemoradiation in Indian patients with locally advanced non-small cell lung cancers. Patients with stage Illa, normal weight or overweight, and adequate baseline pulmonary function should be offered concurrent chemoradiation.
\end{abstract}

Key words: Locally advanced non-small cell Lung cancer, concurrent chemoradiation, developing countries, non-small-cell lung cancer, chemoradiation

\section{Introduction}

Lung cancer remains a major cause of death worldwide with more than 1.1 million deaths per year. ${ }^{[1]}$ Non-small-cell lung cancer (NSCLC) represents more than $80 \%$ of all lung tumors, and approximately $35 \%$ of patients with NSCLC in developed countries present with locally advanced non-metastatic disease. The incidence of lung cancer in developing countries has risen from $31 \%$ in 1980 to $50 \%$ in $2002 .{ }^{[2]}$ In India, it is the second commonest cancer in urban males. ${ }^{[3]}$ Most patients present in advanced stages and the intent of treatment is palliative. ${ }^{[4]}$ Since the mid-1990s, the standard treatment for patients with locally advanced non metastatic disease was thoracic radiotherapy and then combined radiochemotherapy. The NSCLC Collaborative Group meta-analysis and the meta-analysis of platin-based concomitant chemotherapy in NSCLC demonstrated that adding sequential or concomitant chemotherapy to radical radiotherapy improved survival in locally advanced NSCLC. ${ }^{[5,6]}$ The hazard ratio (HR) for survival resulting from the addition of sequential chemotherapy to radiotherapy was 0.88 (95\% CI, 0.81-0.96). The HR resulting from the addition of platin-based concomitant chemotherapy to radiotherapy was 0.89 (95\% CI, 0.81-0.98). Several NSCLC trials and

Department of Radiotherapy, Sanjay Gandhi Post Graduate Institute of Medical Sciences, Lucknow, India

Correspondence to: Dr. Sushma Agrawal,

E-mail: sushmaagrawal@yahoo.co.uk

\begin{tabular}{|l|l|}
\hline \multicolumn{2}{|c|}{ Access this article online } \\
\hline Quick Response Code: & Website: \\
\hline & www.sajc.org \\
\cline { 2 - 3 } & \\
\hline
\end{tabular}

meta-analysis have compared sequential and concomitant combinations directly, almost all of which showed a trend in favor of concomitant radiochemotherapy. ${ }^{[5,6]}$ However, some authors still believe that more evidence is required to prove the superiority of concurrent chemoradiation due to heterogeneity of the included trials in the meta-analysis, low patient numbers and lack of statistical power. ${ }^{[7]}$ Most of the data supporting this observation comes from the developed world and rarely have good-quality clinical trials been carried out in developing countries. Applicability of the results of randomized studies in clinical practice in developing countries is not known. It is, therefore, of paramount importance to put the experience of the developed world into the context of the limited resources and other health care problems of developing countries. ${ }^{[8]}$ Outcomes with chemoradiotherapy in Indian patients with locally advanced lung cancer have been rarely reported. ${ }^{[9]}$

There are various challenges in treatment of locally advanced lung cancer especially in the context of developing countries. Hence the purpose of this review is to highlight the various challenges in optimizing chemoradiation in locally advanced NSCLC and evaluate its applicability in developing countries based on our audit of outcomes with chemoradiation in patients with locally advanced lung cancer over 5 years.

\section{Tumor and patient heterogeneity}

Locally advanced NSCLC is a heterogeneous disease which explains the large differences in treatment outcome between patients. The stage subdivision in IIIA and IIIB varies considerably depending on tumor size, location and nodal involvement. A large number of patients with more advanced or metastatic disease may be included in this subset based on CT scan findings, if not ruled out as metastatic disease by PETCT. ${ }^{[10]}$ PETCT is still available in only select metropolitan cities in such a vast country and hence accurate staging of these patients is a challenge in our country. Positivity of radiologically 
enlarged mediastinal lymphnodes should be proven by endobronchial ultrasound guided or transbronchial cytology. Availability of endobronchial ultrasound-guided cytology is also a challenge in our country. Out of 495 patients registered in our department over 5 years (2007-2011), only $55(11 \%)$ patients with stage III disease were suitable for radical chemoradiation (based on radiological staging with CT scan and excluding patients with frank pleural effusion). Among these only 16 (29\%) had stage IIIA disease and $39(71 \%)$ had stage IIIB disease. Based on the guidelines for eligibility for chemoradiation in developing countries only those with IIIA should be offered concurrent chemoradiation, but since the superiority of concurrent chemoradiation over sequential chemoradiation were preliminary at the time when we embarked on concurrent chemoradiation, $63 \%$ patients were treated with concurrent chemoradiation with an intent to offer superior treatment ${ }^{[11]}$ Those with poor performance status, greater weight loss and bulkier disease were treated with sequential chemoradiation. ${ }^{[11]}$ This data reflects that the majority of patients of NSCLC (89\%) present in advanced stages and are unfit for any radical treatment at the time of presentation, which can be attributed to illiteracy, lack of awareness and resources for early detection of lung cancers in our country.

\section{Clinical factors}

Clinical factors such as weight loss, performance status, comorbidity and cardiopulmonary reserves will influence tolerance to treatment and outcome in NSCLC. Comorbidity is frequently observed in elderly patients and in smokers, two groups with a high incidence of lung cancer. These patients often receive less aggressive treatment. ${ }^{[12,13]}$ More than half of the patients with stage III are currently thought to be ineligible for concurrent regimens, if inclusion is restricted to patients less than 75 years and those with less than two serious comorbidities. ${ }^{[14]}$ However, comorbidity does not correlate per se with treatment outcome in patients fit enough for chemoradiation therapy (CRT). ${ }^{[15]}$ In a prospective study of 203 patients with locally advanced NSCLC, prognostic factors like age, sex, ethnicity, smoking status, performance status, body mass index (BMI), forced expiratory volume in 1 minute $\left(\mathrm{FEV}_{1}\right)$, use of FDG-PET scan, stage (IIIA versus IIIB) and baseline hemoglobin were analyzed to find out factors associated with better outcomes. On multivariate analysis, baseline hemoglobin $(>12 \mathrm{~g} / \mathrm{dl})$ and $\mathrm{FEV}_{1}$ more than 2 lt predicted favorable outcomes in patients treated with chemoradiation. ${ }^{[16]}$ The median age of our patients was 62 years and the median survival of patients less than 65 years age was 12 months as compared to 10 months with more than 65 years age. On multivariate analysis $\mathrm{FEV}_{1}$ more than $2 \mathrm{lt}$, BMI and radiotherapy dose predicted favorable outcomes. Those with $\mathrm{FEV}_{1}$ more than 2 lt had a median survival of 36 months versus 12 months for $\mathrm{FEV}_{1}$ less than $2 \mathrm{lt}$, BMI overweight had median survival of 24 months versus 12 and 6 months with normal and underweight and radiotherapy dose more than 50 Gy predicted better survival than that with less than 50 Gy. Patients with stage IIIA had a median survival of 23 months as compared to 12 months with Stage IIIB. Performance status, weight loss and stage did not show prognostic significance.

\section{Chemotherapy schedule}

There is still no consensus on which cytotoxic drug combinations are the standard of care for sequential chemotherapy. No two studies included in various meta-analyses on outcomes of concurrent versus sequential chemoradiotherapy have similar drug combinations in the sequential arm. For sequential chemotherapy poor patients received cisplatin etoposide combination, patients coming from far places were offered carboplatin paclitaxel combination and those who had to travel shorter distance were offered cisplatin gemcitabine combination. However, all the above mentioned cytotoxic drugs were well-tolerated by Indian patients. Another challenge in developing countries is lack of health insurance policy for the vast population, resulting in difficulty in delivering similar cytotoxic drugs across the population which in turn leads to difficulty in interpretation of outcome. Also the government funding agencies for research as a policy do not support costs of chemotherapy drugs required for conducting clinical trials for cancer care, where the same regimen can be given to all the patients for ensuring uniform treatment and meaningful interpretation of outcomes.

\section{Choice of concomitant drugs}

There is still no consensus on which cytotoxic drug combinations and schedule of drug delivery are the standard of care for concomitant chemoradiotherapy. At present platinum-based polychemotherapy is considered the standard. Apart from the radio-sensitizing effects, cytotoxic agents may influence cell cycle synchronization, prevent tumor cell repopulation and inhibit DNA repair to hypoxic cell sensitization. Drugs such as cisplatin and carboplatin are frequently used in combination CRT Cisplatin can be given in low daily dose or in higher doses in a weekly or three weekly regimen. Cisplatin is active as a radio sensitizer but this has not been shown clearly for carboplatin. ${ }^{[17,18]}$ For practical reasons, however, carboplatin-based doublets are often used. The second agent varies and its choice should be based on its toxicity profile. Etoposide, vinorelbine and taxanes do not show any unexpected toxicity in studies reported so far and are thus good candidates to be added to the platin compound. Incorporation of newer cytotoxic drugs and targeted agents are being explored for their potential role in the treatment of locally advanced NSCLC. In a JCOG study evaluating induction chemotherapy followed by gefitinib and concurrent thoracic radiotherapy for unresectable locally advanced adenocarcinoma of the lung, toxicity was acceptable and the median survival time was 28.5 months. ${ }^{[19]}$ In another study where patients were stratified based on risk categories into good risk and 
poor risk groups. Patients with good risk were treated with concurrent gefitinib $250 \mathrm{mg}$ daily and weekly paclitaxel $50 \mathrm{mg} / \mathrm{m}^{2}$ plus carboplatin AUC 2 and those with poor risk with concurrent gefitinib $250 \mathrm{mg}$ daily along with RT (66 Gy). Survival of poor-risk patients with wild type or mutated EGFR receiving sequential CRT with gefitinib was promising. Survival for good-risk patients receiving concurrent CRT plus gefitinib was disappointing even for tumors with activating EGFR mutations. ${ }^{[20]}$ Although this strategy is less toxic, only data of feasibility studies are available. This strategy is attractive for our population because of higher incidence of EGFR mutation status in Asians but availability of EGFR mutation status is a challenge in our country and hence outcomes with concurrent EGFR tyrosine kinase inhibitors are not available for our population.

In our patients concurrent chemotherapy with cisplatin etoposide combination as per the SWOG protocol showed $80 \%$ compliance and hence can be safely delivered. ${ }^{[21]}$ The popularity of carboplatin paclitaxel combination in US, when tested in two of our patients resulted in fungal pneumonia leading to death. Therefore, this regimen has been further abandoned in our setup but is being used in some centres in our country. Literature on radiation pneumonitis also suggests that this combination results in higher incidence of radiation pneumonitis. ${ }^{[22]}$ Hence use of this combination is advisable in centers with resources to tackle these complications.

\section{Radiotherapy}

Thoracic radiotherapy is an integral component of treatment in locally advanced NSCLC as it is responsible for local disease control and contributes to improved survival. In the Radiation Therapy Oncology Group (RTOG73-01) study using two-dimensional treatment techniques, 376 patients were randomized between a radiation dose of 40 Gy split course and a continuous fractionation schedule of 40,50 , or $60 \mathrm{~Gy} .{ }^{[23]}$ The intrathoracic failure rates at 3 years in these arms were 44, 52, 42, and 33\%. A higher dose resulted in a greater proportion of complete responses, resulting in a higher tumor control. Dose escalation using conventional fractionation schedules has the disadvantage that the overall treatment time will increase considerably. However, dose escalation can be performed using hyperfractionation. This approach was tested by the RTOG 83-11 study when fractions of 1.2 Gy were given twice daily. ${ }^{[24]}$ Patients were randomized to receive a total dose of $60,64.8,69.6,74.4$, and 79.2 Gy. Survival improved in patients irradiated with 69.6 Gy compared with lower doses but no improvement was seen with doses above $69.6 \mathrm{~Gy}$. This unexpected effect in the highest dose groups could be due to the higher number of delays in treatment in the highest dose groups. In a large phase III trial, using two-dimensional radiotherapy, 563 patients were randomized between standard radiotherapy of $60 \mathrm{~Gy} / 6$ weeks and continuous hyperfractionated accelerated radiotherapy or CHART (54 Gy given in 36 fractions, three fractions daily, of $1.5 \mathrm{~Gy}$ with an overall treatment time of 12 days). ${ }^{[25]}$ A significant improvement of 2-year survival was seen in the CHART regimen (29\%) compared to the conventional arm (20\%). In addition, a significant reduction in local tumor progression was seen in the CHART arm. This trial illustrated that a reduction in overall treatment time increased the tumor control probability and survival in lung cancer patients but at the cost of higher esophagitis.

The outcome of radiotherapy treatment is dependent on accurate delineation of the tumor area and all involved lymph nodes and adequate treatment planning strategies. The radiation dose has remained the same for many years due to technical factors, normal tissue complications and recent $\mathrm{RTOG}$ results of dose escalation showing no improvement in outcomes beyond 66 Gy. The preliminary results of a phase III trial that compared conventionally fractionated standard-dose TRT (60 Gy) with high-dose TRT (74 Gy) revealed an inferior survival outcome among patients assigned to the high-dose arm. ${ }^{[26]}$ Innovations such as the introduction of three-dimensional conformal planning, the use of multileaf collimators, four-dimensional planning CT scans, intensity modulated radiation therapy (IMRT) and image-guided radiation therapy (IGRT) techniques have improved targeting of the tumor volume. This allows the administration of higher radiation doses while reducing the exposure of healthy tissues and thus the risk of normal organ damage. ${ }^{[27,28]}$ The organs at risk during radiation therapy are the lungs, the heart, the spinal cord and the esophagus. The above-mentioned new techniques allows the use of (boost) doses of radiation up to 74-94 Gy, depending on generally accepted dose constraints, such as the mean lung dose. ${ }^{[27,29,30]}$ Radiotherapy dosimetric parameters are the most effective tools for predicting radiation-related lung damage (V20 and mean lung dose $).{ }^{[31,32]}$ For those patients who are considered to be at a high risk for side-effects, a sequential approach of induction chemotherapy followed by radiation therapy is recommended. At present, patients with stage III disease, who present with large tumor volumes, are precluded from high-dose concurrent CRT. These patients can roughly be divided into those presenting with bulky mediastinal disease and/or multilevel lymph node (N3) involvement and patients in whom the primary tumor is located in the periphery of the lung with extended involvement of mediastinal lymph nodes. ${ }^{[33]}$ There is a high chance of distant metastasis at presentation in these patients. In patients with significant weight loss or abnormal serum biochemistry, and those with poor lung function, treatment is aimed at achieving local control until subclinical metastases become obvious, but the tumors are often so large that local control is unlikely and growth delay is the only realistic aim. Tumors $3.5 \mathrm{~cm}$ in diameter have a local control rate of $50 \%$ after radical radiotherapy (wwy in 20-30 fractions) and 50\% of patients with tumors of this size subsequently develop metastases. ${ }^{[34]}$ Larger tumors are associated with significantly poorer results. The 
mean tumor size of patients treated with chemoradiation in our setup was $7 \mathrm{~cm}$ and hence the median survival was poor (12 months). The median survival of patients with comorbidities with concurrent chemoradiation with IMRT and IGRT is 19 months. ${ }^{[15]}$ In our country the above-mentioned innovations are available only in select metropolitan cities, while $75 \%$ of our population is rural. Secondly as per our audit only one third of patients with locally advanced non-small cell lung cancers present as stage IIIA (which comprises only $3.2 \%$ of all lung cancer patients presenting to us in the clinic), who are ideal candidates for such radical radiotherapy with 3DCRT, IMRT, and IGRT. Hence lack of such facilities hardly impacts on the overall outcomes of all lung cancer patients, though presence of such facilities is required to cater to the select few suitable for such treatment. Hyperfractionated treatment is not advisable in countries with limited resources as these patients require intensive care to deal with side-effects.

Patients who already have or are likely to develop significant thoracic symptoms should be treated with local palliative radiotherapy. A recently updated Cochrane review has shown that for good performance status patients higher doses of local radiotherapy appear to be associated with longer survival. ${ }^{[35]}$ The largest trial that only recruited good PS patients showed a 2-month improvement in median survival and a $5 \%$ increase in 1-year survival (36\% vs. $31 \%$ ) for patients treated with 39 Gy in 13 fractions compared to those treated with 17 Gy in 2 fractions. ${ }^{[36,37]}$

\section{Compliance and toxicity}

In a Czech study comparing sequential versus concurrent chemoradiation in locally advanced NSCLC, 64\% of patients in the sequential arm actually received radiotherapy because $30 \%$ patients developed progression of disease on chemotherapy. ${ }^{[38]}$ Furuse, in a similar comparison reported only $25 \%$ compliance with cisplatin, mitomycin, and vindesine combination as sequential treatment. ${ }^{[39]}$ In our patients treatment compliance was $80 \%$ for both sequential as well as concurrent chemoradiation. The incidence of severe granulocytopenia (grade 3) with sequential chemotherapy was $15 \%$ which is similar to $17 \%$ reported in the EORTC study. ${ }^{[40]}$ These toxicities can be easily managed in countries with limited resources.

Concurrent chemoradiation has been reported to result in higher rates of esophagitis (19\%). Use of concurrent chemoradiation resulted in 37\% incidence of esophagitis (grades 2 and 3 ) in our patients. Recognition and admission of such patients for symptomatic management is important, as out-patient management of such patients may lead to noncompliance to feeding instructions and further morbidity. The incidence of symptomatic pneumonitis (requiring steroids) was 38\% in our patients which is similar (35\%) to that reported by the RTOG. ${ }^{[41]}$ The higher incidence of pneumonitis observed in RTOG study has been attributed to carboplatin paclitaxel combination. ${ }^{[22]}$ The higher incidence of pneumonitis observed in our patients can be explained by the inclusion of $36 \%$ patients with $\mathrm{FEV}_{1} 1-2$ lt and $14 \%$ with $\mathrm{FEV}_{1}$ less than $1 \mathrm{lt}$. Only $25 \%$ of patients receiving concurrent chemoradiation had $\mathrm{FEV}_{1}>2 \mathrm{lt}$ and $\mathrm{FEV}_{1}$ was unknown in $25 \%$ patients. Adequacy of $\mathrm{FEV}_{1}(>2 \mathrm{lt})$ is an essential criterion for including patients for concurrent chemoradiation Patients with inadequate FEV 1 1-2 lt should be treated with sequential chemoradiotherapy in developing countries. Palliative radiotherapy regimes should be offered to patients with stage IIIB, $\mathrm{FEV}_{1}<1 \mathrm{lt}$, poor performance status and in those with chest symptoms in developing countries.

\section{Sequence of treatment}

Several meta-analyses have concluded that concurrent chemoradiation is superior to sequential chemoradiotherapy at the cost of increased toxicity. But the criticism of these meta-analyses is the heterogeneity of treatment protocols across these trials, the low patient numbers and the lack of statistical power which limits the interpretation of the results. Even though the median survival reported for the concurrent treatment schedules was uniform across all studies at 16-17 months, with survival ranging from 13 to 15 months in the sequential arms, some authors are of the opinion that concurrent chemoradiation should not be accepted as the standard of care based on the available evidence. ${ }^{[7,42]}$

Our audit on outcomes with chemoradiation revealed that the median survival was 12 months with both sequential and concurrent treatment. This was because of inclusion of patients with poorer $\mathrm{FEV}_{1}$, normal weight BMI, stage IIIB patients, and few elderly patients (age 70-75 yrs) for concurrent chemoradiation. Timely management of grade 3 esophagitis, pneumonitis and better resources could have salvaged few patients on concurrent chemoradiation. Lack of endobronchial cytology facility for histopathological confirmation of radiologically enlarged mediastinal nodes and of PET-CT facility in our centre could be other reason for poor survival. Also in patients with superior sulcus tumors, surgical resection after radical chemoradiotherapy could have led to better outcomes. ${ }^{[43]}$ The only reported randomized Indian study by Dasgupta which compared outcomes with radical radiotherapy versus sequential chemoradiotherapy versus concurrent chemoradiotherapy had $75 \%$ patients with stage III A and the reported progression free survival of 21 months is the highest survival with concurrent chemoradiation reported in the world. ${ }^{[8]}$ Additionally the pertinent toxicities like esophagitis and radiation pneumonitis have not been mentioned.

\section{Chemoradiotherapy followed by surgery}

Chemoradiotherapy has been used as induction therapy, although most often with modest radiation doses in patients with superior sulcus tumours. A subset of patients might be identified who benefit from surgery after CRT. ${ }^{[44,45]}$ Patients who present with vertebra, subclavian vessel or brachial plexus involvement are unsuitable for such treatment. Surgical resection should be considered for patients who 
become resectable or have downstaging of $\mathrm{N} 2$ mediastinal disease after sequential or concurrent chemoradiotherapy, both from a curative and palliative perspective. Thirty percent of patients presenting with superior sulcus tumors are fit to receive combined modality treatment, out of which $50 \%$ of patients are technically resectable. Patients with comorbidity, poor cardiopulmonary reserve and poor performance status do not tolerate concurrent chemoradiotherapy. Pathological complete response after CRT varies from 31 to $47 \%$. Higher radiotherapy dose of 66 Gy has shown higher pathological response. There is improvement in local disease control ( $77 \%$ at 2 years) and survival (70\% at 2 years) after surgical resection. ${ }^{[46]}$

Surgical resection after chemoradiotherapy requires a dedicated thoracic surgery team, which is available only in few centers in our country. The outcomes with surgical resection after chemoradiotherapy in superior sulcus tumors are not available in our country. There is need for optimization of surgery after chemoradiotherapy in our setup.

\section{Locally advanced lung cancer in elderly}

Thirty to $40 \%$ of cases are diagnosed in patients aged more than 70 years. Data from the Surveillance, Epidemiology, and End Results (SEER) registry indicate that the median age at diagnosis in NSCLC patients is 69 years. ${ }^{[4]]}$ Age 70 years is considered a cutoff point for elderly in clinical trials in oncology. Data from the SEER database show that most elderly patients did not receive combined modality treatment. ${ }^{[48]}$ This reflects the uncertainty about concurrent chemoradiation as a treatment of choice for elderly patients with locally advanced NSCLC.

One phase III elderly-specific trial has evaluated chemoradiation versus RT alone. ${ }^{[49]}$ Patients were randomly assigned to RT (60 Gy) alone or to the chemoradiation arm (same RT with concurrent use of carboplatin $30 \mathrm{mg} / \mathrm{m}^{2}$ ). This trial was closed early because of deaths in combined modality arm. The Radiation Therapy Oncology Group (RTOG) pooled together the results of 749 NSCLC patients participating on three separate RTOG trials. These patients had received RT alone; hyperfractionated RT (hRT); induction platinum-based therapy, followed by either RT alone or concurrent CMRT or concurrent CMRT with hRT. One hundred and fourteen patients (15\%) were more than 70 years of age. The authors reported that as therapy intensified, the incidence of grades 3-5 toxic effects increased in elderly population. They found no significant difference in survival between treatment arms in these elderly patients. The conclusion was that unlike the overall patient population, elderly patients did not benefit from increased therapeutic intensity and that sequential or concurrent CRT showed less, if any, benefit over RT alone for elderly patients. ${ }^{[50]}$ According to the EORTC Elderly Task Force and Lung Cancer Group and International Society for Geriatric Oncology (SIOG) experts' opinion for the treatment of NSCLC in an elderly population concurrent CRT approach should be offered to elderly patients with locally advanced NSCLC. But because of lack of evidence of randomized trials and higher risk of toxicity in elderly patients, treatment decision should be based on PS, absence of significant comorbid diseases and patient life expectancy. ${ }^{[51]}$

In our center $10 \%$ of locally advanced lung cancer patients were elderly, out of which few were treated with chemoradiation and few with radiotherapy alone. The median survival was 14 months with radiotherapy as well as chemoradiation. Chemotherapy was poorly tolerated in this group.

\section{Conclusions}

Sequential chemoradiotherapy is better tolerated than concurrent chemoradiation in Indian patients with locally advanced NSCLC. Patients with stage IIIA, normal weight or overweight, and adequate baseline pulmonary function should be offered concurrent chemoradiation.

\section{References}

1. Ferlay J, Bray F, Pisani P, Parkin DM. GLOBOCAN 2002: Cancer Incidence, Mortality and Prevalence Worldwide. IARC Cancer Base No. 5. Version 2.0, Lyon: IARC Press; 2004.

2. Parkin DM, Bray F, Ferlay J, Pisani P. Global cancer statistics, 2002. CA Cancer J Clin 2005;55:74-108.

3. National Cancer Registry Programme (NCRP). A Consolidated report of the population based cancer registries data, cancer statistics 2002-2006, Indian Council of Medical Research, New Delhi.

4. Behera D, Balamugesh T. Lung cancer in India. Indian J Chest Dis Allied Sci 2004;46:269-81.

5. Non-small Cell Lung Cancer Collaborative Group. Chemotherapy in non-small cell lung cancer: A meta-analysis using updated data on individual patients from 52 randomised clinical trials. BMJ 1995;311:899-909.

6. Auperin A, Le Pechoux C, Pignon JP, Koning C, Jeremic B, Clamon G, et al. On behalf of the Meta-Analysis of cisplatin/carboplatin based Concomitant Chemotherapy in non-small cell Lung Cancer (MAC3-LC) Group. Concomitant radiochemotherapy based on platin compounds in patients with locally advanced non-small cell lung cancer (NSCLC): A meta-analysis of individual data from 1764 patients. Ann Oncol 2006; 17:473-83.

7. O'Rourke N, Macbeth F. Is concurrent chemoradiation the standard of care for locally advanced non-small cell lung cancer? A review of guidelines and evidence. Clin Oncol 2010;22:347-55.

8. Kepka L, Casas F, Perin B, Abdel-Wahab S, Saghatelyan T, Vashkevitch L, et al. Radiochemotherapy for lung cancer in developing countries. Clinn Oncol 2009;21:536-42.

9. Dasgupta A, Dasgupta C, Basu S, Majumdar A. A prospective and randomized study of radiotherapy, sequential chemotherapy radiotherapy and concomitant chemotherapy-radiotherapy in unresectable non small cell carcinoma of the lung. J Cancer Res Ther 2006;2:47-51.

10. Behzadi A, Ung Y, Lowe V, Deschamps C. The role of positron emission tomography in the management of non-small cell lung cancer. Can J Surg 2009;52:235-42.

11. Macbeth FR, Abratt RP, Cho KH, Stephens RJ, Jeremic B, International Atomic Energy Agency. Lung cancer management in limited resource settings: Guidelines for appropriate good care. Radiother Oncol 2007;82:123-31.

12. Chen KY, Chen JH, Shih JY, Yang CH, Yu CJ, Yang PC. Octogenarians with advanced non small cell lung cancer: Treatment modalities, survival and prognostic factors. J Thorac Oncol 2010;5:82-9.

13. Casas F, Kepka L, Agarwal JP, Dawotola D, Gaye P, Abdel-Wahab S, et al. Radiochemotherapy in the elderly with lung cancer. Expert Rev Anticancer Ther 2009;9:1405-11.

14. De Ruysscher D, Botterweck A, Dirx M, Pijls-Johannesma M, Wanders R, Hochstenbag $M$, et al. Eligibility for concurrent 
chemotherapy and radiotherapy of locally advanced lung cancer patients: A prospective, population-based study. Ann Oncol 2009;20:98-102.

15. Phernambucq EC, Spoelstra FO, Verbakel WF, Postmus PE, Melissant CF, Maassen van den Brink KI, et al. Outcomes of concurrent chemoradiotherapy in patients with stage III non-small-cell lung cancer and significant comorbidity. Ann Oncol 2011;22:132-8.

16. Ademuyiwa FO, Johnson CS, White AS, Breen TE, Harvey J, Neubauer M, et al. Prognostic factors in stage III non-small cell lung cancer. Clin Lung Cancer 2007;8:478-82.

17. Cakir S, Egehan I. A randomised clinical trial of radiotherapy plus cisplatin versus radiotherapy alone in stage III nonsmall cell lung cancer. Lung Cancer 2004;43:309-16.

18. Clamon G, Herndon J, Cooper R, Chang AY, Rosenman J, Green MR. Radiosensitization with carboplatin for patients with unresectable stage III non-small-cell lung cancer: A phase III trial of the Cancer and Leukemia Group B and the Eastern Cooperative Oncology Group. J Clin Oncol 1999; 17:4-11.

19. Niho S, Ohe Y, Ishikura S, Atagi S, Yokoyama A, Ichinose Y, et al. Induction chemotherapy followed by gefitinib and concurrent thoracic radiotherapy for unresectable locally advanced adenocarcinoma of the lung: A multicenter feasibility study (JCOG 0402). Ann Oncol 2012;23:2253-8

20. Ready N, Jänne PA, Bogart J, Dipetrillo T, Garst J, Graziano S, et al. Chemoradiotherapy and gefitinib in stage III non-small cell lung cancer with epidermal growth factor receptor and KRAS mutation analysis: Cancer and leukemia group B (CALGB) 30106, a CALGB-stratified phase II trial. J Thorac Oncol 2010;5:1382-90.

21. Kathy SA, John JC, Andrew TT III, David RG, William BF, Joseph IC. Concurrent cisplatin, etoposide, and chest radiotherapy in pathologic stage IIIB no-small-cell lung cancer: A Southwest Oncology Group Phase II Study, SWOG 9019. J Clin Oncol 2002;20:3454-60.

22. Palma DA, Senan S, Tsujino K, Barriger RB, Rengan R, Moreno M, et al. Predicting radiation pneumonitis after chemoradiation therapy for lung cancer: An international individual patient data meta-analysis. Int J Radiat Oncol Biol Phys 2013;85:444-50.

23. Perez CA, Bauer M, Edelstein S, Gillespie BW, Birch R. Impact of tumor control on survival in carcinoma of the lung treated with irradiation. Int J Radiat Oncol Biol Phys 1986; 12:539-47.

24. Cox JD, Pajak TF, Asbell S, Russell AH, Pederson J, Byhardt RW, et al. Interruptions of high-dose radiation therapy decrease long-term survival of favorable patients with unresectable non-small cell carcinoma of the lung: Analysis of 1244 cases from 3 Radiation Therapy Oncology Group (RTOG) trials. Int J Radiat Oncol Biol Phys 1993;27:493-8.

25. Saunders M, Dische S, Barrett A, Harvey A, Gibson D, Parmar M. Continuous hyperfractionated accelerated radiotherapy (CHART) versus conventional radiotherapy in non-small-cell lung cancer: A randomized multicentre trial. CHART Steering Committee. Lancet 1997;350: 161-5.

26. Bradley J, Paulus R, Paulus R, Curran WJ, Robert F, Fossella F et al. A randomized phase III comparison of standard-dose ( $60 \mathrm{~Gy}$ ) versus high-dose (74 Gy) conformal chemoradiotherapy +/- cetuximab for stage IIla/IIlb non-small cell lung cancer: Preliminary findings on radiation dose in RTOG 0617. Int J Radiat Oncol Biol Phys 2011;81(Suppl): 176.

27. Elderbos JS, Heemsbergen WD, De Jaeger K, Baas P, Lebesque JV. Final results of a Phase I/II dose escalation trial in non small-cell lung cancer using three-dimensional conformal radiotherapy. Int J Radiat Oncol Biol Phys 2006;66:126-34.

28. Liao ZX, Komaki RR, Thames HD Jr, Liu HH, Tucker SL, Mohan R, et al. Influence of technologic advances on outcomes in patients with unresectable, locally advanced non small-cell lung cancer receiving concomitant chemoradiotherapy. Int J Radiat Oncol Biol Phys 2010;76:775-81.

29. Bradley JD, Bae K, Graham MV, Byhardt R, Govindan R, Fowler J, et al. Primary analysis of the phase llcomponent of a phase I/II dose intensification study using three-dimensional conformal radiation therapy and concurrent chemotherapy for patients with inoperable non small-cell lung cancer: RTOG 0117. J Clin Oncol
2010;28:2475-80.

30. Stinchcombe TE, Morris DE, Lee CB, Moore DT, Hayes DN, Halle JS, et al. Induction chemotherapy with carboplatin, irinotecan, and paclitaxel followed by high dose three-dimension conformal thoracic radiotherapy (74 Gy) with concurrent carboplatin, paclitaxel, and gefitinib in unresectable stage IIIA and stage IIIB nonsmall cell lung cancer. J Thorac Oncol 2008;3:250-7.

31. Kwa SL, Lebesque JV, Theuws JC, Marks LB, Munley MT, Bentel G, et al. Radiation pneumonitis as a function of mean lung dose: An analysis of pooled data of 540 patients. Int J Radiat Oncol Biol Phys 1998;42:1-9.

32. van Baardwijk A, Bosmans G, Boersma L, Wanders S, Dekker A, Dingemans AM, et al. Individualized radical radiotherapy of non-small-cell lung cancer based on normal tissue dose constraints: A feasibility study. Int J Radiat Oncol Biol Phys 2008;71:1394-401.

33. Baas P, Belderbos JS, van den Heuvel M. Chemoradiation therapy in nonsmall cell lung cancer. Curr Opin Oncol 2011;23:140-9.

34. Abratt RP. Modelling tumour and treated lung volume influences in the irradiation of non-small-cell lung cancer patients. Int J Radiat Oncol Biol Phys 2001;49:481-5.

35. Lester J, Coles B, Macbeth FR, Toy E. Palliative radiotherapy for non-small cell lung cancer. Cochrane Database Syst Rev 2006;4:CD002143.

36. Macbeth FR, Bolger JJ, Hopwood P, Bleehen NM, Cartmell J, Girling DJ, et al. Randomized trial of palliative two-fraction versus more intensive 13-fraction radiotherapy for patients with inoperable non-small cell lung cancer and good performance status. Medical Research Council Lung Cancer Working Party. Clin Oncol 1996;8: 167-75.

37. Medical Research Council Lung Cancer Working Party. Randomised trial of palliative two fraction versus more intensive 13 fraction radiotherapy for patients with inoperable non-small cell lung cancer (NSCLC) and good performance status. Clin Oncol 1996;8:167-75

38. Zatloukal P, Petruzelka L, Zemanova M, Havel L, Janku F, Judas L, et al. Concurrent versus sequential chemoradiotherapy with cisplatin and vinorelbine in locally advanced non-small cell lung cancer: A randomized study. Lung Cancer 2004;46:87-98.

39. Furuse K, Fukuoka M, Kawahara M, Nishikawa H, Takada Y, Kudoh S, et al. Phase III study of concurrent versus sequential thoracic radiotherapy in combination with mitomycin, vindesine, and cisplatin in unresectable stage III non-small-cell lung cancer. J Clin Oncol 1999; 17:2692-9.

40. Belderbos J, Uitterhoeve L, van Zandwijk N, Belderbos $\mathrm{H}$, Rodrigus $\mathrm{P}$, van de Vaart $\mathrm{P}$, et al. Randomised trial of sequential versus concurrent chemo-radiotherapy in patients with inoperable non-small cell lung cancer (EORTC 08972-22973). Eur J Cancer 2007;43:114-21.

41. Werner-Wasik M, Paulus R, Curran WJ Jr, Byhardt R. Acute Esophagitis and late lung toxicity in concurrent chemoradiotherapy trials in patients with locally advanced non-small-cell lung cancer: Analysis of the radiation therapy oncology group (RTOG) database. Clin Lung Cancer 2011;12:245-51.

42. Aupe'rin A, Le Pe'choux C, Rolland E, Curran WJ, Furuse K, Fournel $\mathrm{P}$, et al. Meta-analysis of concomitant versus sequential radiochemotherapy in locally advanced non-small-cell lung cancer. J Clin Oncol 2010:28:2181-90.

43. Kappers I, Belderbos JS, Burgers JA, van Zandwijk N, Groen HJ, Klomp HM. Non-small cell lung carcinoma of the superior sulcus: favorable outcomes of combined modality treatment in carefully selected patients. Lung Cancer 2008;59:385-90.

44. Friedel G, Budach W, Dippon J, Spengler W, Eschmann SM, Pfannenberg $\mathrm{C}$, et al. Phase II trial of a trimodality regimen for stage III non-small-cell lung cancer using chemotherapy as induction treatment with concurrent hyperfractionated chemoradiation with carboplatin and paclitaxel followed by subsequent resection: A single-center study. J Clin Oncol 2010;28:942-8.

45. Kappers I, Belderbos JS, Burgers JA, van Zandwijk N, Groen HJ, Klomp HM, et al. Non-small cell lung carcinoma of the superior sulcus: Favorable outcomes of combined modality treatment in carefully selected patients. Lung Cancer 2008;59:385-90

46. Rusch VW, Giroux DJ, Kraut MJ, Crowly J, Hazuka M, Winton T, 
et al. Induction chemoradiation and surgical resection for superior sulcus nonsmall cell lung carcinoma: Long term survival results of Southwest oncology group trial 9416(Intergroup trial 0160). J Clin Oncol 2007;25:313-8.

47. Havlik RJ, Yancik R, Long S, Ries L, Edwards B. The National Institute on Aging and the National Cancer Institute SEER collaborative study on comorbidity and early diagnosis of cancer in the elderly. Cancer 1994;74 (7 Suppl):2101-6.

48. Davidoff AJ, Gardner JF, Seal B, Edelman MJ, Wedding U, Lacombe D. Population-based estimates of survival benefit associated with combined modality therapy in elderly patients with locally advanced non-small cell lung cancer. J Thorac Oncol 2011;6:934-41.

49. Atagi S, Kawahara M, Tamura T, Noda K, Watanabe K, Yokoyama A, et al. Standard thoracic radiotherapy with or without concurrent daily low-dose carboplatin in elderly patients with locally advanced non-small cell lung cancer: A phase III trial of the Japan Clinical Oncology Group (JCOG9812). Jpn J Clin Oncol 2005;35: 195-201.

50. Langer C, Scott C, Byhatdt R,Werner-Wasik M. Effect of advanced age on outcome in Radiation Therapy Oncology Group studies of locally advanced NSCLC (LANSCLC). Lung Cancer 2000;29:104.

51. Pallis AG, Gridelli C, van Meerbeeck JP, Greillier L, Wedding U, Lacombe D, et al. EORTC Elderly Task Force and Lung Cancer Group and International Society for Geriatric Oncology (SIOG) experts' opinion for the treatment of non-small-cell lung cancer in an elderly population. Ann Oncol 2010;21:692-706.

How to cite this article: Agrawal S. Challenges in optimizing chemoradiation in locally advanced non small-cell lung cancers in India. South Asian J Cancer 2013;2:265-71.

Source of Support: Nil. Conflict of Interest: None declared.

\title{
News
}

\begin{tabular}{|c|}
\hline 30th ICON Meeting 2014 \\
For further details please contact \\
Dr. Khurshid Mistry \\
Email: khurshid.mistry@oncologyindia.org \\
31st ICON Meeting 2014 \\
Bhopal, MP \\
For further details please contact: \\
Dr. TP Sahoo \\
Email: Tarini73@rediffmail.com \\
Dr. Khurshid Mistry \\
Email: khurshid.mistry@oncologyindia.org
\end{tabular}

\section{News}

\author{
Calling all stakeholders in the fight against Cancer \\ Can-India Conclave \\ Thursday 19th to Saturday 21st December 2013 \\ Auditorium Complex, Tata Memorial Hospital, Mumbai \\ and Multi Activity Center, Indian Cancer Society Rehabilitation Center, Mumbai \\ National Conference of Cancer NGOs and Support Groups \\ - Conference \\ - Workshops (4) \\ - Poster Presentations \\ - Display of NGOs activities and products (Can-Market) \\ - Awards in 10 categories (nominations open) \\ - Entertainment competition for Cancer Survivors \\ Website: www.cancerNGOs.org \\ Email: info@cancerNGOs.org
}

\section{Staying in touch with the journal}

1) Table of Contents (TOC) email alert Receive an email alert containing the TOC when a new complete issue of the journal is made available online. To register for TOC alerts go to www.sajc.org/signup.asp.

2) RSS feeds

Really Simple Syndication (RSS) helps you to get alerts on new publication right on your desktop without going to the journal's website. You need a software (e.g. RSSReader, Feed Demon, FeedReader, My Yahoo!, NewsGator and NewzCrawler) to get advantage of this tool. RSS feeds can also be read through FireFox or Microsoft Outlook 2007. Once any of these small (and mostly free) software is installed, add www.sajc.org/rssfeed.asp as one of the feeds. 